\title{
Escrita, memória e cuidado - testemunhos de trabalhadores de saúde na pandemia
}

\section{Writing, memory and care - health workers testimonies in times of pandemic}

\author{
Octavio Domont de Serpa Jr.*1, Nuria Malajovich Muñoz ${ }^{* 2}$, \\ Ana Cléris Morais Silva*3, Bárbara Monique Pereira da Silva Leal*4, \\ Bruna Romano Gomes*5, Clarice Cezar Cabral*6, \\ Maria Tereza Thomas Vargas ${ }^{* 7}$, Marina Bistriche Giuntini*8, \\ Rosalba Lopes ${ }^{* 9}$, Erotildes Maria Leal ${ }^{* 10}$
}

Apresentamos, no presente artigo, o percurso teórico e prático que envolveu a criação do projeto Pausas e Pousos - Vivências do Trabalhador de Saúde em Tempos de Pandemia. A inciativa tem por objetivo conhecer as vivências dos trabalhadores de saúde na pandemia de COVID-19, no cenário nacional. Apresentamos o modo de conhecimento narrativo e o testemunho como uma modalidade particular de produção narrativa, examinando modalidades morais da recepção de testemunhos de profissionais de saúde. Discutimos ainda como o uso de plataformas digitais pode servir como recurso para a produção de memória. Por último, descrevemos a construção de um espaço de escrita, memória, cuidado e diálogo através de intervenções artísticas em ferramentas digitais, afirmando a aposta no poder que o compartilhamento de histórias pode exercer sobre as angústias e sofrimentos emocionais dos trabalhadores de saúde.

Palavras-chave: Testemunho, midias sociais, trabalhadores de saúde, COVID-19

*1, 2, 3, 5, 6, 8, 10 Universidade Federal do Rio de Janeiro - UFRJ (Rio de Janeiro, RJ, Brasil).

*4 Centro de Atenção Psicossocial Paulo Marcos Costa (São Gonçalo, RJ, Brasil).

*7 Prática privada e consultoria organizacional. (Rio de Janeiro, RJ, Brasil).

*9 Pesquisadora autônoma. (Belo Horizonte, MG, Brasil). 


\section{Introdução}

Vivemos um ano ruim. Muito ruim. Um ano de pandemia, em que a vida, supremo bem que governa nossas relações (Fassin, 2018), a vida de todos e de cada um (mais a de uns do que a de outros), se vê ameaçada e em risco. Estamos expostos ao contágio de SARS-CoV-2, e às suas consequências para a saúde, e ao contágio emocional produzido pelo medo, incertezas, informações conflitantes, evitação, estigmatização, adoecimentos e perdas (Huremovic, 2019). Fomos lançados em uma forma de vida, que conjuga recomendações de higiene, práticas de distanciamento social e quarentena, interações virtuais e trabalho remoto intensivo. Usamos a ideia de forma de vida como Fassin (2018): um operador que articula o biológico e o biográfico, o universal e o particular, a regra e a prática, permitindo assim enxergar a vida, a cor local, o toque pessoal, sob as diretrizes e orientações gerais.

Os impactos psicossociais da pandemia atingem a todos, em especial alguns subgrupos: profissionais de saúde (prioritariamente os que estão à frente de ações de cuidado); portadores de doenças crônicas, de transtornos mentais; sobreviventes da infecção; famílias enlutadas; idosos; crianças; pessoas que vivem sozinhas; pessoas em situação de rua; moradores de áreas desprovidas de condições de saneamento básico mínimas; trabalhadores precarizados etc. Não surpreende que apareçam ou se intensifiquem experiências de sofrimento psíquico, tanto na população em geral quanto entre os profissionais de saúde.

Vivemos um ano ruim. Mais um de uma longa história, com eventos recentes de destruição do meio ambiente, de produção de desigualdades sociais e econômicas, de opressões e violência estrutural. $\mathrm{O}$ sofrimento mental associado às experiências da pandemia se une a uma dimensão anterior: de sofrimento social. A pandemia expõe que o sofrimento e dano variam na proporção direta da vulnerabilidade de cada sujeito, sabendo que a vulnerabilidade não diz respeito exclusivamente a aspectos individuais (The Lancet, 
2020): os efeitos maiores de uma pandemia, tanto nos seus aspectos somáticos quanto psicossociais, têm classe social, têm cor e têm gênero.

A iniciativa que apresentaremos neste trabalho foi a resposta dos autores - a maioria profissional de saúde mental, atuando ou não diretamente no cuidado - imersos, como todos, nesta forma de vida pandêmica, aos desafios e interrogações deste modo inédito de experiência coletiva.

O projeto Pausas e Pousos - Vivências do Trabalhador de Saúde em Tempos de Pandemia tem por objetivo conhecer suas experiências, no cenário nacional, possibilitando que as histórias vividas sejam contadas, compartilhadas e divulgadas, oferecendo um lugar de pouso para relatos daquilo que de alguma forma os marcou. O blog https://pausasepousos.tumblr.com/, criado em maio de 2020, publica textos que podem ser enviados como mensagem de voz ou de texto pelo Instagram (@pausaspousos), Facebook (https://www.facebook. com/pausaspousos/) ou email (narrativasemtempocovid@gmail.com). Uma artista plástica — Zina Leal ${ }^{1}$ — dialoga com os relatos, oferecendo imagens criadas para o projeto. Aposta-se no poder de cuidado em saúde mental que o compartilhamento de histórias pode exercer sobre as angústias e sofrimentos emocionais dos trabalhadores de saúde.

Para o leitor que não conhece o Pausas e Pousos, recomendamos a visita aos endereços eletrônicos, antes de continuar a leitura. $\mathrm{O}$ artigo inicia apresentando o modo de conhecimento narrativo, seus elementos constituintes, sua força performativa e sua relação com a subjetividade, para em seguida se debruçar sobre o testemunho como uma forma particular de produção narrativa. Na sequência, examinaremos modalidades morais da recepção de testemunhos de profissionais de saúde, e finalizaremos apresentando como criamos um espaço de escrita, memória e cuidado a partir das ferramentas digitais.

\section{Por que histórias?}

Manguel (2018) se interroga sobre "como as histórias que contamos nos ajudam a perceber a nós mesmos e aos outros" (p. 7). Ricoeur (1990) e Bruner (2014) indicam que a subjetividade, em seus estratos mais complexos,

\footnotetext{
${ }^{1}$ Para conhecer o trabalho da artista, ver a sua página no Instagram (@a.zinaleal) ou Facebook (https://www.facebook.com/a.zinaleal/).
} 


\section{ARTIGOS}

é constantemente tecida por meio de narrativas, estabelecendo a ideia do eu como produção que deriva da capacidade de fabricar e contar histórias sobre nós mesmos. Ao contrário de outras atividades e funções humanas - respirar, comer, dormir — para narrar "[...] precisamos dos outros [...] para que nos devolvam o que dissemos" (Manguel, 2018, p. 10). A história que tece e sustenta o eu narrativo é necessariamente relacional. $\mathrm{O}$ eu não é $o$ seu próprio autor quanto à existência, sendo apenas um dos coautores quanto ao sentido (Ricoeur, 1990).

Importante frisar que o sujeito narrativo não é uma abstração. Ele é corporificado e situado (Menary, 2008). A ancoragem corporal da experiência subjetiva estrutura a perspectiva interna contínua no tempo, dotando a experiência de uma qualidade pré-narrativa, de uma "demanda por narrativa" (Kerby, 1993). Como lembra Ricoeur (1990), a narrativa faz parte da vida antes de se exilar na escrita.

Bruner (2014) e Frank (2010) se interrogam sobre os elementos mínimos que compõem a estrutura narrativa - agente, ação, objeto, direção, e temporalidade - articulados em um enredo, no qual um problema procura resolução. Bruner (2014) sugere que o que guia uma história é um desajuste entre seus elementos. As histórias são impulsionadas por um problema e, nesse sentido, a criação de uma história responde tanto à resolução de um problema quanto à sua formulação.

Buscar os elementos da narrativa pode criar questionamentos acerca do direito de cidadania de narrativas que não os contenham todos, mas não responde às perguntas: por que e para que narrativas?

Narrativas são provocadas pelo inesperado, como a forma de vida insólita, ameaçadora, cruel, em que fomos todos lançados este ano. Ricoeur (1990) e Bruner (1990) convergem no entendimento de que o dom da narrativa é ligado à possibilidade de fabricar histórias como um meio de conciliação com o inesperado e com o desconhecido. Um modo de se arranjar com o inassimilável da condição humana, de domesticar o imprevisível, um aspecto crucial da interação social e da esperança na construção de um espaço comum mais amigável onde habitar. Narrativas elaboram uma concordância discordante, sintetizando o heterogêneo por meio da mediação entre os eventos, a ação e o encadeamento da história narrada (Ricoeur, 1990).

Bruner (1986) examina o que chama de "dois modos de pensamento" que ordenam a experiência, e constroem a realidade. O modo lógico-dedutivo dos relatórios técnicos e científicos (Frank, 2010), que busca correspondência com a realidade, coerência da argumentação e são geralmente impessoais, escritos sem ponto de vista; e o modo das histórias bem contadas, das narrativas, sentido trabalhado nesta seção, cujos elementos estruturais 
aludimos acima. Estas estabelecem conexões entre eventos particulares, aspiram à verossimilhança. São histórias que se tornam verdadeiras na medida em que são contadas (Frank, 2010), "[...] ficções inventadas, que partem da descoberta de verdades históricas e sociais que podem ganhar realidade por meios narrativos" (Manguel, 2018, p. 84).

Para responder à pergunta: por que a criação de um espaço virtual para receber, guardar, compartilhar narrativas de profissionais de saúde? Vamos ver então o que fazem as histórias, como e quais efeitos produzem.

Bruner (1986) reconhece a força das histórias na sua capacidade de "subjuntivar" a realidade. No lugar das certezas, a abertura de um campo de possibilidades. O pensamento monológico dá lugar à abertura de um espaço de diálogos (Frank, 2010). Quem lê ou ouve uma história é incluído no seu processo de construção permanente, tornando-se também narrador/autor provocado a usar a sua imaginação: "[...] leitores diferentes criam histórias diferentes por meio de suas leituras" (Manguel, 2018, p. 82). A capacidade de subjuntivação das histórias advém de algumas de suas características. Histórias trabalham com pressuposições ou significados implícitos, o que as torna abertas à múltiplas interpretações. É o que Frank (2010) vai chamar

624 de suspense: caráter aberto e indeterminado, que pode gerar diversos modos de compreensão e dar margem à concepção de diferentes desfechos ou antecedentes para a trama narrada. Histórias são contadas a partir de um ponto de vista, podendo acolher múltiplas perspectivas em uma mesma narrativa. Esses pontos de vista, seja de um narrador ou de algum personagem, são sempre marcados por algum modo de implicação moral e tonalidade afetiva. Finalmente, histórias são ressonantes ou intertextuais (Frank, 2010), sempre ecoam outras histórias. Ninguém conta, ou ouve, uma história por si mesmo, "do zero". Histórias remetem a outras histórias, já contadas ou que ainda serão, num entrelaçar infinito que fortalece os vínculos do leitor/narrador com seu tempo, sua história, sua cultura.

\section{Testemunho e prática narrativa}

Kahn e Huremović (2019) retomam a história das pandemias e referem uma tendência geral ao esquecimento, uma vez que sua crise é superada. O avanço da doença gera incerteza e caos na população, causando desconforto existencial que faz com que memórias e experiências sejam diferentemente incorporadas e se tornem passíveis de amnésia coletiva. 
Zelando para que as vivências dos trabalhadores de saúde no enfrentamento à pandemia não sejam esquecidas, criamos Pausas e Pousos como um espaço de acolhimento, produção de cuidado e compartilhamento de histórias que marcaram esses profissionais na lida nos serviços de saúde. Dar destaque ao saber depreendido dessa experiência e valorizar as histórias desses profissionais é uma forma de retribuir o cuidado prestado à população e nos solidarizar com os desafios, riscos e perdas por eles enfrentados. Fazer justiça ao saber experiencial desses profissionais se insere em uma perspectiva marcada pelo modo narrativo de conhecimento, forma privilegiada de estar em relação e aprender com os outros (Serpa Jr., 2017).

O espaço do blog é também forma de cuidado com os profissionais de saúde que adoeceram, uma forma de lembrança e homenagem àqueles que faleceram e são lembrados com carinho pelos colegas, um momento de despedida e de luto pelos pacientes que se foram, mas também campo de reflexão, aprendizado e transmissão da experiência subjetiva do cuidar.

Fricker (2007) traz contribuições importantes sobre atribuição de sentido e valor à experiência de outras pessoas. Ela aponta que algumas narrativas ganham mais valor do que outras, silenciando aquelas produzidas por grupos destituídos de poder social, gerando uma injustiça epistêmica. Uma atitude epistemicamente justa é aquela que leva em conta a contribuição narrativa das pessoas em toda a sua diversidade à produção, disseminação e manutenção do conhecimento. Para que as pessoas possam ter sua voz escutada e suas narrativas sejam consideradas produto de um sujeito do conhecimento, é preciso uma postura inclusiva e ativa na criação de recursos coletivos interpretativos que alarguem nossa capacidade de descrever, compreender e validar vivências específicas.

Vivências extremas, como situações-limite ou de intenso sofrimento psíquico, podem ser difíceis de narrar, de dividir com os outros. Benjamin (1985) apontava em 1936 os estragos causados pela Primeira Grande Guerra nos ex-combatentes. Voltavam mudos dos campos de batalha, sem expressar ou intercambiar o que haviam experimentado. Os impactos da Segunda Guerra Mundial não foram menores, deixando marcas profundas no mundo contemporâneo. Diante dos horrores do Holocausto, surge o testemunho enquanto gênero literário que marca o impossível de narrar e a necessidade de memória, de registro do incontável e do impensável na história da civilização.

Laub (1992), psicanalista e pesquisador do Holocausto, mostra a importância do testemunho como via de reconstrução de uma vida possível, após as atrocidades impostas pela guerra, para sobreviventes de campos de concentração. A solidão e a falta de reconhecimento social em relação a 
vivências de perda e dor gera profundo mal-estar e impede a realização da elaboração subjetiva da experiência vivida.

$\mathrm{O}$ autor aponta a necessidade de construção de metodologias para tratar de experiências que não podem ser contadas em sua íntegra. Afirma que determinadas experiências são duras demais para serem postas em palavras. Sua possibilidade de transmissão depende de uma acolhida cuidadosa e respeitosa, que dê lugar aos silêncios, pausas, lacunas da memória e contradições discursivas. Estas são pontes de acesso importantes ao testemunho de experiências subjetivas dolorosas.

O testemunho é um recurso narrativo que permite ao narrador explorar situações vividas que não são inteiramente transmitidas pela via discursiva, recorrendo a uma memória que é sempre parcial, lacunar e fragmentada (Agamben, 2008). Como mostra Seligmann-Silva (2005), não são tanto o relato dos fatos que conta, mas a estranheza que causam, o modo como perturbam e alteram o cotidiano.

Fazer justiça epistêmica a pessoas que passaram por situações traumáticas e de grande impacto emocional implica validar aquilo que suas narrativas transmitem em palavras e dar lugar àquilo que carece de inscrição 626 (Laub, 1992). Em estudo com sobreviventes do Holocausto com história de transtornos psiquiátricos, Laub (2005) denuncia a grave injustiça testemunhal sofrida por essas pessoas. Muitos, diagnosticados com esquizofrenia, foram ouvidos com desinteresse pelas equipes sobre as situações por eles vividas antes de suas internações. $O$ autor sustenta que muitos desses pacientes sofriam de estresse pós-traumático e teriam tido suas internações evitadas, caso tivessem tido a chance de compartilhar abertamente suas histórias.

Ressaltamos com Laub (1992) a necessidade de criação de uma comunidade de testemunho que ofereça um pouso para histórias e vivências diversas a serem transmitidas e legitimadas. Narrativas sobre experiências vividas ajudam pessoas a refletir sobre suas próprias histórias, a encontrar saídas para suas dificuldades, a rever padrões e lugares sociais, a denunciar certas práticas e atitudes e a promover a empatia e cuidado solidário.

Dar lugar a vivências de perda e dor não é sem consequências para quem oferece espaço de cuidado e acolhida a essas narrativas. A história contada institui um processo dialógico entre o narrador/emissor e o leitor/ouvinte a quem a narrativa se destina. Acolher o testemunho implica fazer-se também contador da história, o que requer disposição para lidar com seu próprio silêncio, dores e inquietações.

Ellis (2013), seguindo Laub, realiza pesquisa narrativa com sobreviventes do Holocausto por meio do testemunho colaborativo. Tendo como 
norte a ética do cuidado, a autora defende a relação empática como forma de produção de conhecimento dialógico. Sua investigação se insere em uma perspectiva que não se quer isenta ou neutra. Com forte preocupação política, aproxima-se do ativismo social na luta por direitos e condições sociais iguais, denunciando a violência a que certos grupos são submetidos. Essas narrativas ganham forma e lugar, contribuindo para a construção de modos solidários de enfrentamento de experiências difíceis, de grande sofrimento e não são inteiramente traduzidas.

A ampliação do acervo narrativo é fundamental para o desenvolvimento de uma postura empática, solidária e epistemicamente justa em nossa sociedade. As narrativas, exercendo a função de testemunho, provocam ressonâncias no ouvinte/leitor. Sua veiculação é fundamental para que atinja e toque um público maior, que se afeta e transforma pela experiência e perspectiva do outro, ampliando a capacidade coletiva de ver e sentir. A narrativa, assim nos faz viajar mundos, para usar a bela expressão de Lugones (1987), indicando a importância de se dispor a mergulhar com flexibilidade e respeito no mundo do outro.

Lugar de pouso e intercâmbio de vivências, o blog tem intenção de oferecer um momento de descanso, reflexão, troca e compartilhamento com os pares e novos parceiros. Desde outros campos de conhecimento, abre-se o diálogo e o encontro com esses profissionais através de seus escritos e trabalhos artísticos. As narrativas depositadas em Pausas e Pousos constituem acervo testemunhal que reflete a dureza de uma época, mas também a beleza dos encontros e do trabalho solidário.

\section{Heróis?}

"Ontem no trem, voltando do trabalho, veio no /meu pensamento:

'Vamos às atividades do dia:

Lavar os copos,

Contar os corpos

"E sorrir'*

Não fui eu que formulei essa frase.

Paro e penso.

* (Criolo - música Lion Man) 
Não dá pra considerar que faz parte das atividades do dia contar corpos. Não dá!

$[\ldots]$

Sigo pensando."

Marina, Terapeuta Ocupacional

"E quando a gente sente a tristeza todinha do mundo em nós?

Hoje chegou forte o tédio, o nojo, a tristeza, a impaciência.

Como você, em confinamento, lida com isso?

É livre?

Onde pousa minha liberdade?

- Conseguiu contar as ambulâncias hoje?

Não tô conseguindo nem contar a minha vida, vou contar as ambulâncias?

Onde pousa minha liberdade?"

Breno, Psicólogo

"Mesmo em CTI, dividindo o sono conturbado dos 'bips' eternos juntos. Em conexão. Fui la' dar-lhe a resposta de que sr. José estava bem e que estava atrás dela, dormindo cabeça com cabeça. Sua felicidade foi estoteante e uma lágrima de valor peroláceo correu de sua face. 'Obrigada, doutor. Melhor notícia que recebi'. Eu sou romântico sem vergonha de assumir. Daqueles piegas a Lorde Byron. Mas esse é o amor que quero. $O$ amor do sono feliz com os 'bips'eternos."

Álvaro, Médico

Acima, três fragmentos de narrativas de trabalhadores recebidas no Pausas e Pousos. O testemunho é poderoso. Mas o que mais se conhece sobre a experiência do trabalhador de saúde no cenário da pandemia quando as narrativas em primeira pessoa são tomadas em perspectiva e em conjunto com narrativas, em terceira pessoa, que contam sobre o trabalho desses profissionais?

$\mathrm{Na}$ literatura científica, revisões sustentam que trabalhadores de saúde na pandemia têm sido duramente afetados em sua saúde mental e física (Pappa, 2020; Spoorty, 2020; Oliveira, 2020). Depressão, ansiedade, insônia, dor de cabeça estão entre os sintomas mais citados nessa população, grupo de risco também para a COVID-19. No editorial da Nature Medicine, de maio de 2020, o estresse entre os trabalhadores de saúde foi 
citado como uma outra pandemia, oculta, dentro da pandemia da COVID-19 (Krystal \& McNeil Jr., 2020).

Os trabalhadores de saúde também têm sido narrados como heróis na mídia, por organizações de saúde como a OMS e, com menos força, na literatura científica (Berger \& Ghadimi, 2020; Bauchner, 2020; Ng, 2020). Quem não acompanhou as diversas homenagens que receberam em vários lugares do mundo? Por eles se cantou em sacadas, matérias de gratidão foram publicadas e foram narrados como guerreiros, combatentes da linha de frente, soldados da batalha e, consequentemente, heróis de uma guerra. Vidas "ofertadas" para salvar outras vidas, a despeito do pouco conhecimento sobre o vírus, das precárias condições de trabalho, da ausência de equipamentos de proteção individual adequados e suficientes. Esses aspectos foram considerados, na mídia e na literatura especializada, determinantes do sofrimento físico e mental.

Cox (2020), em um pequeno artigo, explicitou algumas das consequências éticas dessa narrativa (Lewis, 2020; Higgins, 2020, Berger, 2020; Edberg, 2020; Barron, 2020). O heroísmo individual, destacado e requerido desses profissionais, dissimularia os deveres da sociedade e dos governos para com eles, para com suas condições de trabalho e sistemas de saúde, bem como para com o modelo de enfrentamento da pandemia enquanto fenômeno social, de responsabilidade coletiva. Certa ideia de que aos trabalhadores caberia se entregar de corpo e alma, de modo abnegado, à tarefa do cuidar, foi gestada, a despeito do contraponto ouvido especialmente nas mídias sociais. Como fenômeno correlato, sustenta Cox, os outros atores dessa cena - governos, instituições sociais, de saúde e população — foram desresponsabilizados. Diante da força dos heróis, os outros se tornaram passivos figurantes. A autora destaca ainda os efeitos negativos dessa narrativa sobre a saúde física e mental desses trabalhadores.

$\mathrm{O}$ vivido experimentado pelos trabalhadores, narrado em primeira pessoa, posto face a face com narrativas em terceira pessoa, expressa na literatura científica e leiga, se adensa e ganha outros contornos. O "rastreamento de sinais, indícios, signos" (Guinsburg, 1989, p. 177) ampliam a compreensão da experiência vivida, embora não a apreenda em sua integridade. Detalhes e particularidades supostamente contingentes nas vidas e nos acontecimentos narrados por cada um, aparentemente insignificantes ou significantes apenas para aquele narrador, revelaram aspectos do fenômeno mais geral da experiência vivida dos trabalhadores de saúde no cenário nacional da pandemia.

A recusa da identidade do herói - quer em seus aspectos laudatórios ou negativos - observada nas narrativas dos trabalhadores de saúde, denunciam 
as armadilhas dessa descrição. Haider (2019), com seu livro Armadilhas da identidade: raça e classe nos dias de hoje, contribui para a circunscrição do oculto revelado. As narrativas dos trabalhadores explicitam as relações concretas que se operam entre o vivido e as determinações materiais da vida social.

Há experiências narradas que destacam sim a dimensão de satisfação de dever cumprido ao cuidar, mas essas seriam melhor descritas pela figura do cuidador ferido (Zerubavel \& Wright, 2012). A identidade de herói, como narrada na pandemia, destaca o trabalhador de saúde da materialidade do mundo e lhes subtrai a possibilidade de experienciar, com legitimidade, desespero, desesperança e outros sentimentos valorados como negativos. Nesse sentido, o cuidador ferido aparece como um arquétipo mais poroso, imerso em relações sociais concretas, que, ao recuperar a historicidade do vivido, resiste à desumanização favorecida pela identidade do herói. A complexidade das vivências narradas é prenhe de humanidade, concreta, real, experienciada e enraizada no mundo que habitam. Os afetos tristes e desesperançados que colorem as narrativas em primeira pessoa, ou aqueles que rompem a própria identidade do trabalhador colocando-o empaticamente próximo de quem é cuidado, como o amor, a compaixão, ou mesmo o medo, a angústia, a raiva ou a resiliência, comovem e guardam poesia. A narração das experiências, quer aflitas, angustiadas, ou mesmo epifânicas, reconecta o trabalhador com o mundo vivido, primariamente intersubjetivo, determinado e sustentado por relações concretas de trabalho e vida. A violência a que os trabalhadores de saúde estão submetidos na pandemia, em território nacional, tanto quanto os mecanismos cotidianos de resistência, tornam-se visíveis. Entre nós, os limites do conhecimento sobre a COVID-19, os seus desfechos, somando à ausência de políticas públicas de saúde e sociais para o enfrentamento da pandemia ganham perspectivas particulares.

Cabrini e colaboradores (2020 discorreram sobre o avesso da identidade do herói: a estigmatização dos profissionais de saúde que, com a evolução da pandemia, passaram de heróis a ameaças. As experiências narradas no Pausas e Pousos não descrevem nada semelhante ao relato desses autores: profissionais de saúde, de diferentes países, com acesso negado a transporte público, lojas, e até vítimas de agressão física. Na Lombardia, o Centro de Coordenação da COVID-19 decidiu investir em pesquisa exploratória sobre o tema, tamanha a magnitude do problema, extensivo também aos familiares dos trabalhadores. Entre nós o que se dá é diferente, embora pareça um outro avesso da identidade do herói. Aqui os relatos contam de sentimentos quase permanentes de ser ameaça para familiares, amigos e sociedade. Essas experiências, determinadas socialmente, não raro são vividas exclusivamente como marcas pessoais. Se e quando projetadas para fora das relações 
concretas que as sustentam, o que faz delas ponto de chegada e saída, o que se percebe é a amplificação do mal-estar (Zerubavel \& Wright, 2012).

As narrativas dos trabalhadores, tomada em perspectiva, convidam então a um exame mais apurado do mal-estar experimentado cotidianamente e descrito como estresse, ansiedade e depressão, por quem vive e por quem observa. Quando tais palavras são usadas pelos trabalhadores, sob o enquadre do vivido, não se esgotam em si mesmas. Mesmo quando narradas prioritariamente a partir das marcas pessoais, o testemunho revela sua rede de produção. Se na perspectiva da terceira pessoa o mal-estar é, aparentemente, ponto de partida e chegada, na perspectiva da primeira pessoa, destacam-se as circunstâncias que o produzem e determinam. Nesse sentido, a categoria sofrimento social circunscreve melhor o que se revela na dimensão experiencial.

O conceito de sofrimento social (Kleinman, Das \& Lock,1997) se faz lente para a observação das relações estabelecidas entre determinadas experiências subjetivas de mal-estar e processos históricos mais amplos (Pussetti \& Brassabeni, 2011). O que se ressalta, nessa visada, são os modos como as pessoas experimentam o seu poder e/ou a falta dele, e as práticas e estratégias utilizadas para definir e aliviar o mal-estar, produzidas e sustentadas no jogo das relações. O sofrimento social é resultante de relações de poder violentas atualizadas não por um indivíduo ou grupo, mas pela própria estrutura de poder. Nessa perspectiva, as experiências de sofrimento individuais, situadas e corporificadas, decorrem das limitações da capacidade de ação dos sujeitos diante dessas forças que os constrangem. Em cenário nacional, a pandemia ganhou contornos específicos. O modelo de enfrentamento desse fenômeno social entre nós, pautado na passividade e na minimização dos seus efeitos, tanto por parte das autoridades de governo quanto da população, determinou contornos particulares à violência estrutural experimentada pelos trabalhadores de saúde. Os testemunhos nos ofereceram a possibilidade de compreender como se dá essa violência e seus impactos sobre a experiência cotidiana. Revelou-se como cada um, nos seus cenários de vida e trabalho, têm seguido sofrendo e resistindo a partir dos constrangimentos impostos à vida.

\section{Plataformas digitais para produção de memória}

O distanciamento social, recomendado pelas instituições de saúde como uma das formas mais eficazes de prevenção da COVID-19, colocou a 
necessidade de inventarmos outras formas de viver, trabalhar, estudar e cuidar. A internet tornou-se ferramenta aliada para a produção de novos modos de vida e de contato com o outro, como família, rede comunitária e acesso a notícias. Se antes a internet poderia ser considerada uma janela aberta ao mundo, hoje nos é requerido pensá-la como um direito à cidadania.

Atônitos com as mudanças que o distanciamento social e as medidas sanitárias nos impunham, nos perguntamos como contribuir com a circulação de informação e cuidado. Era intenção do projeto oferecer pouso para as vivências dos profissionais e pausa para a reflexão sobre as estratégias de lida com desafios vividos: não ceder ao automatismo imposto pelo ritmo de trabalho, risco iminente da própria morte, da perda de familiares, amigos e usuários, dentre outros. Outro propósito era produzir um espaço de memória e registro das experiências, de maneira que pudessem ser lembradas e coletivizadas. Para alcançar esses objetivos tomamos como ferramenta de trabalho a internet e suas diversas plataformas digitais.

Desde a sua popularização como ferramenta de comunicação na década de 1990, a internet tornou-se espaço de trocas, socialização, linguagem e memória. Ao lado dos espaços tradicionalmente utilizados, como museus, a internet tem se tornado uma espécie de "lugar de memórias" (Henriques, 2014, p. 24), articulando o compartilhamento de imagens, registros e narrativas, através das redes sociais, junto da digitalização permanente de documentos (Cunha, 2011), possibilitando ao mundo que sua memória se organize em redes, constituindo, uma "grande e larga memória" (p. 103).

Sob esta perspectiva, a internet passou a se oferecer como acervo e como testemunho de vivências, permitindo o seu compartilhamento e lembrança. No blog Pausas e Pousos a experiência pandêmica apareceu em diferentes formas textuais (textos, imagens e áudios). Vindos dos mais diferentes contextos geográficos nacionais (do Xingu ao centro da cidade de São Paulo), de trabalho (hospitais, atenção primária em saúde, serviços especializados), e de diferentes categorias de profissionais de saúde (médicos, enfermeiros, psicólogos, terapeutas ocupacionais etc.) múltiplas vozes contaram diferentes versões da mesma história.

As redes sociais da internet diferem da mídia tradicional, por proporcionarem que não haja a centralização da produção e disseminação de ideias e saberes. Permitem que a história seja contada através da narrativa daqueles que têm acesso às tecnologias. A construção da memória torna-se mais universal, sem ser totalizante, dada a possibilidade de que diferentes vozes participem de sua construção a partir de reminiscências particulares (Cunha, 2011, p. 109). 


\section{ARTIGOS}

Ao considerar que a história pode ser construída pelas narrativas de variados autores, é necessário atentar para a memória enquanto objeto de disputa, não herdada e que, ao ser negociada, pode ser transformada, tornando-se fundamental para o sentimento de continuidade de si e da coletividade (Souza, 2018). Ao proporcionar que o trabalhador da saúde narre suas próprias histórias enquanto sujeito que disputa a criação de memórias, cria-se uma forma de resistência à desvalorização de suas vidas.

$\mathrm{O}$ direito à memória pode ser visto como antídoto àquilo que Bosi (1979) aponta como o efeito mais perverso da pobreza extrema: "a espoliação das lembranças" (p. 443). Nesse sentido, a compreensão da memória como um direito pode oferecer instrumentos potentes para o trabalho com populações marcadas pela miséria, ou que estejam em situações complexas e traumatizantes.

No caso das narrativas publicadas no blog, trata-se de testemunhos de profissionais da saúde que narram o vivido durante a pandemia. Portanto, o sentido afirmativo do registro não se vincula à questão da pobreza e sua superação. No entanto, muitas questões se insinuam: haverá sentido afirmativo neste narrar? Estaremos diante da constituição de fontes que se constroem em 'situação de trauma'? E tantas outras. Por ora, exploramos aquilo que nos parece evidente, como o sentido de antídoto ao esquecimento e o fato de tratar-se de uma rica fonte de pesquisa para aqueles que se debruçarem sobre o estudo das tonalidades locais assumidas por esse fenômeno pandêmico global.

Para um historiador a riqueza desta fonte remete à experiência de Marc Bloch (2011), que ao escrever A estranha derrota no calor do revés sofrido pelos franceses frente aos alemães na Segunda Guerra Mundial, se colocava como uma testemunha. Esse lugar de testemunha, de observador de seu próprio tempo, transformou aquele relato em fonte valiosa para que a posteridade pudesse entender aquele momento histórico (Minella, 2012).

Desde o final da Segunda Guerra e, principalmente, a partir da década de 1990, registraram-se transformações importantes nos diferentes campos da pesquisa histórica. Revalorizou-se a análise qualitativa; resgatou-se a importância das experiências individuais, impulsionou-se a história cultural, renasceu o estudo do político e incorporou-se o estudo do contemporâneo.

A expansão dos debates acerca da memória e de suas relações com a história ofereceu chaves para uma nova inteligibilidade do passado (Rousso, 1993). Ao explorar as relações entre memória e história colocou-se em evidência a construção, pelos atores, de sua própria identidade e reequacionou-se as relações entre passado e presente, reconhecendo que o 
passado é construído segundo as necessidades do presente. Ampliou-se, assim, a possibilidade de aceitação do valor dos testemunhos diretos, encarando-se as possíveis distorções presentes nos depoimentos como uma fonte adicional para a pesquisa.

No campo do que é chamado História Oral acumulou-se rica reflexão que busca oferecer modos de relacionar o individual, presente na narrativa dos sujeitos, à dimensão coletiva. O sujeito individual que recorda é tomado, dessa forma, como alguém socialmente integrado. O acervo em constituição em Pausas e Pousos, ao oferecer ao leitor aquilo que os profissionais de saúde selecionaram para registrar, para ficar como memória, pode desvendar elementos de um "[...] amálgama maior, o da inserção em uma comunidade específica" (Delgado, 2006, p. 51).

Registros desse tipo funcionam, além de testemunhos, como um contraponto a uma aceleração permanente que no mundo contemporâneo produz "um vazio de passado que as operações da memória tentam compensar" (Sarlo, 2007, pp. 95-96) e no qual nada chega a se ossificar. Os relatos em questão revelam operações da memória que podem servir também de contrapeso à normalização que se assiste frente aos números assustadores

634 de mortos no país. As narrativas que pousam no blog recuperam situações específicas, pessoas de carne e osso, possuidoras de nomes, de laços afetivos, de histórias e, nesta medida, também expressam uma reação à constituição daquela imensa mistura desordenada dos mortos sem nome, de que nos fala Camus (2005). Ali encontramos os indivíduos: pacientes, profissionais de saúde, familiares etc., bem como elementos do amálgama social no qual esses profissionais se inserem e do qual fazem parte. Descortinam, portanto, um vasto campo de investigação que pode ajudar a lançar luzes, por exemplo, para a compreensão de uma sociedade que vincula a imagem do profissional de saúde à de um herói, ao mesmo tempo que registra agressões a alguns deles em praça pública. Ou, para dizer o mínimo, tais relatos permitem a reflexão sobre as condições da saúde pública e daqueles que a fazem funcionar neste país que, em termos de política nacional, assumiu uma atitude negacionista frente à pandemia.

\section{Mídias sociais, narrativa e arte}

Encontramos na internet um meio de captação e compartilhamento das narrativas que apresenta ferramentas com funcionalidades variadas, segundo a 
mídia social em questão (Henriques, 2014). O Instagram se constitui como rede relacionada à imagem; chats e Whatsapp tendem a ser mais textuais. Esse saber a respeito do funcionamento de cada um desses recursos se deu para nós como aprendizagem processual, de reconhecimento da dinâmica de cada uma delas.

Os textos completos são publicados no Tumblr, plataforma que possi-bilita a criação de blogs com espaço adequado para textos. No Instagram e Facebook publicamos fragmentos selecionados dos textos, associados às suas respectivas imagens, disponibilizando o link para o Tumblr, caso as pessoas desejem acessar os textos completos. As narrativas têm chegado via Instagram (direct) e Facebook (messenger) $)^{2}$ e, em menor quantidade, via WhatsApp e e-mail.

As postagens são adaptadas às dinâmicas próprias de cada rede social. No Instagram, utilizamos imagem e pequenos trechos dos textos acompanhados de hashtags, para facilitar a localização das publicações através de palavras-chave. 'Stories', publicação que fica disponível por $24 \mathrm{~h}$, tem sido a principal forma de interação com os conteúdos publicados e também um importante meio de comunicação com as pessoas que seguem a página. No Facebook, os trechos dos textos postados são mais longos.

Após o recebimento da narrativa, ela é transcrita, se necessário, e editada. Com mínimas alterações, a edição pretende sanar dúvidas relacionadas ao conteúdo da narrativa e erros. Já nesse momento, os textos frequentemente provocam a equipe. As palavras escolhidas pelo autor, a forma dada ao seu texto, as pontuações e sua linguagem produzem reflexão. Cada "pouso" narrativo é acompanhado por uma imagem criada pela artista plástica colaboradora do projeto e, por vezes, reinterpretada por membros da equipe em um diálogo dinâmico e expressivo, de modo que acolhimento, criação, conexão e afeto entrecruzam-se, pelas vias de comunicação que as múltiplas redes possibilitam.

Nossa metodologia de trabalho envolve um fluxo na organização e distribuição de tarefas, recepção das criações, diálogo com os autores, leitura e reação aos textos, criação e escolha de imagens, até chegar à publicação, propriamente dita. Esse processo se dá de forma fluida e coletiva, como uma composição escrita a muitas mãos, com temas e detalhes que vão se definindo na medida em que a partitura avança, sem um roteiro fixo, ou formato pré-determinado. Um "caminho a ser trilhado", como diria Walter Benjamin

${ }^{2}$ Direct e messenger permitem que uma pessoa envie uma mensagem privada ao administrador da página. Essa é uma maneira de se comunicar com a página sem que a mensagem fique pública. 
(1984, p. 50) sobre a origem da palavra método, em oposição ao método da ciência moderna, que preconiza "um caminho a ser seguido".

O compartilhamento das narrativas nas redes sociais permite fixar no tempo o que é contado, criando "rastros digitais" (Bruno, 2012), o que faz com que a narrativa seja passível de ser potencialmente localizada. Mas, por outro lado, traz o risco de que elas se tornem mero depósito de coisas ditas, sem que se configure necessariamente como memória, devido ao grande volume de variadas informações publicadas diariamente nessas mesmas plataformas (Souza, 2018).

A interlocução remota nos priva da presença de gestos, expressões e tons de voz, as ressonâncias causadas pela leitura das histórias acabam sendo limitadas aos likes e alguns comentários. Essas formas de reação são apenas uma parte das possibilidades de interação de quem tem contato com elas e de criação de memórias. Com o intuito de ampliar as formas de relação com as narrativas, nos fazermos mais tangíveis aos trabalhadores que veiculavam suas histórias em nosso blog e compreender de modo mais profundo como as pessoas são tocadas pelas histórias que leem, realizamos também oficinas e rodas de conversa online, bem como a publicação de "costuras" narrativas, tecidas por uma integrante da equipe, a partir das histórias já publicadas.

A roda de conversa Pausa com Prosa funciona como ambiente virtual de leitura e conversa, tomando como ponto de partida narrativas já publicadas, o que possibilita a discussão sobre diferentes percepções que uma mesma narrativa pode nos provocar ao ser lida coletivamente. A oficina Pouso Criativo traz como proposta um espaço para ouvir e contar histórias, através do uso da arte. Com mediação de integrantes do blog e da artista plástica, partindo das narrativas compartilhadas, os participantes confeccionaram imagens com materiais que possuíam em suas casas.

A arte nos serve de esteio e via de produção de sentido e beleza frente às lacunas e elementos caóticos da realidade que não temos outros meios de abordar ou explicar. Segundo Volz (2016) a arte conecta pessoas e aponta modos inventivos de fazer e lidar com as incertezas. A arte "está fundada na imaginação, e somente através da imaginação seremos capazes de conceber outras narrativas para nosso passado e novos caminhos para o presente" (p. 29). Bazin (1991) aponta que o homem sempre usou a linguagem e, em especial, as imagens, para resgatar e registrar suas memórias, buscando escapar, através destas, da ação do tempo, da morte e do esquecimento.

A linguagem artística introduz novos modos de relação com nossas próprias memórias, possibilitando um processo de reinvenção e movimento 
que integra de modo sui generis o campo da beleza com o horror, "lugar onde arde [...], onde a cinza ainda não apagou" (Didi-Huberman, 2012, p. 214). Vivemos isso de forma muito encarnada no cotidiano das interações para a produção do blog: do encantamento ao desespero a cada post. O blog adere assim a um projeto de cuidado relacional, interconectado e politicamente engajado, no qual textos e imagens são usados como ferramentas para promover a troca e a reciprocidade entre todos os envolvidos. Um cuidado mútuo e mediatizado pelo mundo, marcado pelo potencial dos encontros.

\section{Considerações finais}

Ao receber as histórias, testemunhamos a pandemia a partir de múltiplas vozes. Tornamo-nos testemunhas, pois essas histórias se inscrevem na história de cada integrante do grupo. Responsabilizamo-nos por transmiti-las, apostando que contar mais uma história é disputar os sentidos que podem ser construídos para a pandemia. Isto significa não deixar que as experiências vividas pelos trabalhadores de saúde sejam relegadas ao silêncio, servindo à reprodução de uma história única, contada para fins de manutenção dos poderes estabelecidos. As narrativas do blog, com suas leituras e afetações proporcionam, além do rastro virtual, marcas nas nossas próprias existências individuais e coletivas.

Sendo um meio de trocas de experiências e diálogo, encontro com o outro, produção e preservação de memória, as mídias sociais tornaram-se nosso principal meio de desenvolvimento do projeto e alcance dos profissionais de saúde, em momento em que não é possível realizar encontros pessoais e as condições de produção de cuidado foram modificadas. Disponibilizar espaço nas redes sociais para os trabalhadores de saúde possibilitou criar um repositório virtual, na aposta de que experiências pessoais se transformem em memória coletiva e que as situações vivenciadas pelos trabalhadores não sejam esquecidas, valorizando suas memórias e testemunhando suas histórias.

\section{Referências}

Agamben, G. (2008). O que resta de Auschwitz. São Paulo, SP: Boitempo.

Barron, D. (2020, 21 de Junho). Health Care Workers Don't Want to Be Heroes. We're forced to fill that role because our government has failed to mount an 
adequate response to COVID-19 [Website]. Recuperado de: <https://www. scientificamerican.com/article/health-care-workers-dont-want-to-be-heroes $>$.

Bauchner, H., \& Easley, T. J. (2020). On behalf of the entire editorial and publishing staff of JAMA and the JAMA Network. Health Care Heroes of the COVID-19 Pandemic. JAMA, 10.1001/jama.2020.6197. Advance online publication. $<$ https:// doi.org/10.1001/jama.2020.6197>.

Bazin, A. (1991). Ontologia da imagem fotográfica. In O Cinema. Ensaios (pp. 19-27). São Paulo, SP: Brasiliense.

Benjamim, W. (1984). A origem do drama barroco alemão. (Tradução de Sergio Rouanet). São Paulo, SP: Brasiliense.

Benjamin, W. (1985). O narrador. Considerações sobre a obra de Nikolai Leskov. In Magia e técnica, arte e política. Ensaios sobre literatura e história da cultura (pp. 197-221). São Paulo, SP: Brasiliense.

Berger, D. (2020, 26 de Julho). Please stop calling healthcare workers 'heroes'. It's killing us. The Sydney Morning Herald. Recuperado em 30 jul. 2020 de: <https:// www.smh.com.au/national/please-stop-calling-healthcare-workers-heroes-it-skilling-us-20200723-p55ev2.html>.

Bloch, M. (2011). A estranha derrota. Rio de Janeiro, RJ: Zahar.

638 Bosi, E. (1979). Memória e sociedade: lembrança de velhos. São Paulo, SP: T.A. Editor.

Bruner, J. (1986). Two modes of thought. In Actual minds, possible worlds (pp. 11-43). Cambridge, UK: Harvard University Press.

Bruner, J. (1990). Acts of meaning. Cambridge, UK: Harvard University Press.

Bruner, J. (2014). Fabricando histórias: direito, literatura, vida. São Paulo, SP: Letra e Voz.

Bruno, F. (2012). Rastros digitais sob a perspectiva da teoria ator-rede. Revista FAMECOS - mídia, cultura, tecnologia-Ciências da Comunicação, 19(3), 681-704.

Cabrini, L., G. Grasselli, \& M. Cecconi (2020, jul.). Yesterday heroes, today plague doctors: the dark side of celebration. Intensive Care Medicine, 1, 1-2.

Camus, A. (2005). O primeiro homem. (Tradução de Teresa Bulhões Carvalho da Fonseca Silveira e Maria Luiza Newlands). Rio de Janeiro, RJ: Nova Fronteira.

Cox, C. (2020). "Healthcare heroes": problems with media focus on heroism from healthcare workers during de COVID-19 pandemic. Journal of medical ethics, 46(8), 510-513. Recuperado em 30 jul. 2020 de: <https://www.scientificamerican. com/article/health-care-workers-dont-want-to-be-heroes/ $>$.

Cunha, M. R. (2011). A memória da era da reconexão e do esquecimento. Em questão, $17(2), 101-115$. 


\section{ARTIGOS}

Delgado, L. de A. N. (2006). História oral: memória, tempo, identidade. Belo Horizonte, MG: Autêntica.

Didi-Huberman, G. (2012). Quando as imagens tocam o real. Pós, 2(4), 204-219.

Edberg, D. (2020, 11 de maio). Stop calling health care workers heroes and do something to help them [Weblog]. KevinMD.com. Recuperado em 30 jul. 2020 de: $<$ https://www.kevinmd.com/blog/2020/05/stop-calling-healthcare-workers-heroes-and-do-something-to-help-them.html>.

Ellis, C., \& J. Rawicki (2013). Collaborative witnessing of survival during the holocaust: An exemplar of relational autoethnography. Qualitative Inquiry, 19(5), 366-380.

Fassin, D. (2018). Life: a critical user's manual. Hoboken, NJ: John Wiley \& Sons.

Frank, A. W. (2010). Letting stories breath: a socio-narratology. Chicago, Ill: University of Chicago Press.

Fricker, M. (2007). Epistemic injustice: Power and the ethics of knowing. New York, NY: Oxford University Press.

Ginzburg, C. (1989). Mitos, emblemas, sinais: morfologia e história. (Tradução de Frederico Carotti). São Paulo, SP: Companhia das Letras.

Haider, A. (2019). Armadilha da identidade. Raça e classe nos dias de hoje. São Paulo, SP: Veneta.

Henriques, R. M. N. (2014). Os rastros digitais e a memória dos jovens nas redes sociais. Tese de doutorado, Universidade Federal do Estado do Rio de Janeiro, Centro de Ciências Humanas e Sociais. Recuperado de: <http://www. repositorio-bc.unirio.br:8080/xmlui/bitstream/handle/unirio/12048/DS201403. pdf? sequence $=1>$.

Higgins, C. (2020, 27 de maio). Why we shouldn't be calling our healthcare workers 'heroes'. The Guardian. Recuperado em 30 jul. 2020 de: <https://www. theguardian.com/commentisfree/2020/may/27/healthcare-workers-heros-languageheroism Acesso em 30/07/2020>.

Huremovic, D. (2019). Psychiatry of pandemics: a mental health response to infection outbreak. Gewerbestrasse: Springer Nature.

Kahn, S., \& Huremović, D. (2019). Psychology of the Pandemic. In:. Huremovic, D. (Ed.), Psychiatry of pandemics. A mental health response to infection outbreak (pp. 7-35). New York, NY: Springer.

Kerby, P. (1993). Narrative and the self. Indiana, Ind: Indiana University Press.

Kleinman, A., Das, V., \& Lock, M. (1997). Social Suffering. Berkeley, CA: University of California Press.

Krystal, J., \& McNeil Jr, R. (2020). Responding to the hidden pandemic for healthcare workers: stress. Nature Medicine, 26(5), 639-639. 
Laub, D. (1992). Bearing witness or the vicissitudes of listening. In S. Feldmann e D. Laub (Eds.), Testimony, crises of witnessing in literature, psychoanalysis and History (pp. 57-74). New York, NY/London, UK: Routeledge Taylor and Francis Group.

Laub, D. (2005). From speechlessness to narrative: the casesof Holocaust historians and of psychiatrcally hospitalized survivors. Literature and medicine, 24(2), 253-265.

Lewis, M., Willette, Z.M., \& Park, B. (2020, 21 de maio). Calling health care workers 'heroes' harms all of us. Statnews.com; Recuperado em 30 jul. 2020 de: <https:// www.statnews.com/2020/05/21/calling-health-care-workers-heroes-harms-allof-us/>.

Lugones, M. (1987). Playfulness, "world" - travelling and loving perception. Hypatia, 2(2), 3-19.

Manguel, A. (2018). A cidade das palavras: as histórias que contamos para saber quem somos. São Paulo, SP: Companhia das Letras.

Menary, R. (2008). Embodied narratives. Journal of consciousness studies, 15(6), 63-84.

Minella, J. L. S. (2012). Historiador do imediato. História da historiografia, 5(9), 255-261.

Ng, Q. X., De Deyn, M., Lim, D. Y., Chan, H. W., \& Yeo, W. S. (2020). The wounded healer: A narrative review of the mental health effects of the COVID-19 pandemic on healthcare workers. Asian journal of psychiatry, 54. doi: https://doi. org/10.1016/j.ajp.2020.102258.

Oliveira, W. A. de, Oliveira-Cardoso, É. A. de, Silva, J. L. da, \& Santos, M. A. dos. (2020). Impactos psicológicos e ocupacionais das sucessivas ondas recentes de pandemias em profissionais da saúde: revisão integrativa e lições aprendidas. Estudos de Psicologia (Campinas), 37, e200066. Epub May 18, 2020. <https:// doi.org/10.1590/1982-0275202037e200066>.

Pappa, S., Ntella, V., Giannakas, T., Giannakoulis, V. G., Papoutsi, E., \& Katsaounou, P. (2020). Prevalence of depression, anxiety, and insomnia among healthcare workers during the COVID-19 pandemic: A systematic review and metaanalysis. Brain, behavior, and immunity, 88, 901-907. <https://doi.org/10.1016/j. bbi.2020.05.026>.

Pussetti, C., \& Brazzabeni, M. (2011). Sofrimento social: idiomas da exclusão e políticas do assistencialismo. Etnográfica, 15(3), 467-478. Recuperado em 9 ago. 2020 de: <http://www.scielo.mec.pt/scielo.php?script=sci_arttext\&pid=S0873$65612011000300003 \& \operatorname{lng}=\mathrm{pt} \& \mathrm{t} \operatorname{lng}=>$.

Ricoeur, P. Soi-même comme un autre. Paris, FR: Seuil, 1990. 


\section{ARTIGOS}

Rousso, H. (1993). La mémoire n'est plus ce qu'elle était. In Ecrire l'histoire du temps présent, por Institut d'Histoire du Temps Présent. Paris, FR: CNRS Editions.

Sarlo, B. (2007). Tempo passado: cultura da memória e guinada subjetiva. São Paulo, SP: Companhia das Letras / Belo Horizonte, MG: Editora UFMG.

Seligmann-Silva, M. (2005). Literatura, testemunho e tragédia: pensando algumas diferenças. In $O$ local da diferença: ensaios sobre memória, arte, literatura e tradução (pp. 81-104). São Paulo, SP: Editora 34.

Serpa Jr., O. D., Muñoz, N. M., Lima, B. A., Santos, E. S., Leal, E. M., Silva, L. A., . . \& \& Delgado, P. G. (2017). Relatos de experiências em Recovery: Usuários como tutores, familiares como cuidadores/pesquisadores e efeitos destas práticas em docentes e pesquisadores em saúde mental. Cadernos brasileiros de saúde mental, 9(21), 250-270.

Souza, P. L. A. (2018). Narrativas compartilhadas: o Facebook e a produção de militâncias, memória e esquecimento nos movimentos sociais populares. $31^{\mathrm{a}}$ Reunião Brasileira de Antropologia: Brasília.

Spoorthy, M. S., Pratapa, S. K., \& Mahant, S. (2020). Mental health problems faced by healthcare workers due to the COVID-19 pandemic-A review. Asian journal of psychiatry, 51, 102-119. Advance online publication. Recuperado de: $<\mathrm{https}$ :/ doi.org/10.1016/j.ajp.2020.102119>.

The Lancet (2020). Redefining vulnerability in the era of COVID-19. Lancet, 395(10230), 1089. Recuperado de: <https://doi.org/10.1016/ S0140-6736(20)30757-1>.

Volz, J. (2016). Jornadas Espirais: Incerteza Viva. In Incerteza Viva, $32^{\mathrm{a}}$ Bienal de São Paulo (pp. 21-28). São Paulo: Fundação Bienal de São Paulo. Recuperado em 7 ago. 2020 de: $<$ http://www.bienal.org.br/publicacoes/8077>.

Zerubavel, N., \& Wright, M. O. (2012). The dilemma of the wounded healer. Psychotherapy, 49(4), 482-491. Recuperado de: <https://doi.org/10.1037/ a0027824>.

\section{Resumos}

(Writing, memory and care - testimonies by health in times of pandemic)

This article presents the theoretical and practical path involving the creation of the Pausas e Pousos (Pauses and Landings) Project - Health Worker Experiences in Times of the Pandemic. The initiative aims to take a closer look at the experiences of health workers in the Brazilian scenario of the COVID-19 pandemic. Narrative 
knowledge and testimony are presented as special modalities of narrative production, analyzing the moral modalities of receiving the health professionals' testimonies. The use of digital platforms as a resource for the production of memories was also discussed. Last, we describe the creation of a space for writing, memories, care and dialogue through artistic interventions using digital tools and highlight the power that sharing stories may have on coping with fear and emotional distress of health workers.

Key words: Testimony, social media, health workers, Covid-19

(Écriture, mémoire et soins - témoignages des travailleurs de la santé en temps de pandêmie)

Cet article décrit le cheminement théorique et pratique qui a impliqué la création du projet Pauses et Poses - Expériences de travailleurs de la santé en temps de pandémie. L'initiative vise à connaître les expériences des travailleurs de la santé pendant la pandémie de COVID-19 au Brésil. Nous présentons le mode de connaissance narrative et de témoignage comme un mode particulier de production narrative en examinant les modalités morales de réception des témoignages de professionnels de santé. Ensuite, nous décrivons comment l'utilisation des plateformes digitales peut servir de ressource pour la production de mémoire. Pour finir, nous présentons la construction d'un espace d'écriture, de mémoire, de soins et

642 de dialogue à partir d'interventions artistiques sur les outils numériques, affirmant le pari sur le pouvoir que le partage d'histoires peut exercer sur l'angoisse et la souffrance émotionnelle des travailleurs de la santé.

Mots clés: Témoignage, médias sociaux, travailleurs de la santé, COVID-19

(Escritura, memoria y cuidado - testimonios del trabajador de la salud en tiempos de pandemia)

En este artículo presentamos el camino teórico y práctico de la creación del Proyecto Pausas y Aterrizajes - Experiencias del Trabajador de la Salud en Tiempos de Pandemia. La iniciativa tiene como objetivo conocer las experiencias de los trabajadores de la salud durante la pandemia de COVID-19, en el escenario brasileño. Presentamos el modo de conocimiento narrativo y el testimonio como modalidad particular de producción narrativa, examinando modalidades morales de la recepción de testimonios de los profesionales de la salud. También discutimos cómo el uso de plataformas digitales puede servir como recurso para la producción de memoria. Finalmente, describimos la construcción de un espacio de escritura, memoria, cuidado y diálogo mediante intervenciones artísticas en herramientas digitales, reafirmando el poder que el intercambio de historias puede ejercer sobre la angustia y el sufrimiento emocional de los trabajadores de la salud.

Palabras clave: Testimonio, redes sociales, trabajadores de la salud, COVID-19 


\section{ARTIGOS}

Citação/Citation: Serpa Jr., O. D., Muñoz, N. M., Silva, A. C. M., Leal, B. M. P. da S., Gomes, B. R., Cabral, C. C., Vargas, M. T. T., Giuntini, M. B., Lopes, R., \& Leal, E. M. (2020, setembro). Escrita, memória e cuidado - Testemunhos de trabalhadores de saúde na pandemia. Revista Latinoamericana de Psicopatologia Fundamental, 23(3), 620-645. http:// dx.doi.org/10.1590/1415-4714.2020v23n3p620.11.

Editora/Editor: Profa. Dra. Ana Maria R. G. Oda e Profa. Dra. Sonia Leite

Submetido/Submitted: 14.8 .2020 / 8.14.2020 Aceito/Acepted: 21.8 .2020 / 8.21.2020

Copyright: (C) 2009 Associação Universitária de Pesquisa em Psicopatologia Fundamental/ University Association for Research in Fundamental Psychopathology. Este é um artigo de livre acesso, que permite uso irrestrito, distribuição e reprodução em qualquer meio, desde que o autor e a fonte sejam citados / This is an open-access article, which permits unrestricted use, distribution, and reproduction in any medium, provided the original authors and sources are credited.

Financiamento/Funding: Este trabalho não recebeu apoio / This work received no funding.

Conflito de interesses/Conflict of interest: Os autores declaram que não há conflito de interesses. / The authors declare that there is no conflict of interest.

Octavio Domont de Serpa JR.

Professor associado do Instituto de Psiquiatria da Universidade Federal do Rio de Janeiro UFRJ (Rio de Janeiro, RJ, Br).

Rua Marquês de São Vicente 51/402 - Gávea

22451-047 Rio de Janeiro, RJ, Br.

domserpa@gmail.com

https://orcid.org/0000-0001-6827-4057

\section{Nuria Malajovich MuÑoz}

Professora adjunta do Instituto de Psiquiatria da Universidade Federal do Rio de Janeiro UFRJ (Rio de Janeiro, RJ, Br).

Rua General Glicério 326/603 - Laranjeiras

22245-120 Rio de Janeiro, RJ, Br.

nuriamalajovich@gmail.com

https://orcid.org/0000-0003-3872-818X

Ana Cléris Morais Silva

Graduanda em Psicologia da Universidade Federal do Rio de Janeiro - UFRJ (Rio de Janeiro, RJ, Br).

Rua Aarão Reis, 63 - Santa Teresa

2240-090 Rio de Janeiro, RJ, Br

anaclerismorais@gmail.com

https://orcid.org/0000-0003-2568-5395

Rev. Latinoam. Psicopat. Fund., São Paulo, 23(3), 620-645, set. 2020 
Bárbara Monique Pereira da Silva Leal

Assistente Social no CAPS Paulo Marcos Costa (São Gonçalo, RJ, Br).

Rua Florinda Francisca Domingues, Lote 8 Quadra 31 - Itaipuaçu

24934-080 Maricá, RJ, Br

barbaraleal.as@gmail.com

https://orcid.org/0000-0002-7372-4857

\section{Bruna Romano Gomes}

Terapeuta Ocupacional; Doutoranda Programa de Pós-graduação em Psiquiatria e Saúde Mental - Instituto de Psiquiatria da Universidade Federal do Rio de Janeiro - UFRJ (Rio de Janeiro, RJ, Br).

Rua Carlos de Vasconcelos, 54/307 - Tijuca

20521-059 Rio de Janeiro, RJ, Br

brunaromanogomes@gmail.com

https://orcid.org/0000-0002-2916-8443

\section{Clarice Cezar Cabral}

Psicóloga do Instituto de Psiquiatria da Universidade Federal do Rio de Janeiro - UFRJ (Rio de Janeiro, RJ, Br); Mestre em Atenção Psicossocial.

Rua General Glicério, 95/102 - Laranjeiras

22245-120 Rio de Janeiro, RJ, Br

clarice.cabral@ipub.ufrj.br

644 https://orcid.org/0000-0002-3846-1473

\section{Maria Tereza Thomas Vargas}

Psicóloga; Mestre em Saúde Coletiva - Universidade do Estado do Rio de Janeiro - UERJ (Rio de Janeiro, RJ, Br).

Rua Cruz Lima, 8/602 - Flamengo

22230-010 Rio de Janeiro, RJ, Br

tecavargas@gmail.com

https://orcid.org/0000-0002-2840-3149

\section{Marina Bistriche GiUntini}

Terapeuta Ocupacional; Mestranda do Mestrado Profissional em Atenção Psicossocial - Instituto de Psiquiatria da Universidade Federal do Rio de Janeiro - UFRJ (Rio de Janeiro, RJ, Br). Rua Hermenegildo de Barros, 8/312 - Santa Teresa

20241-040 Rio de Janeiro, RJ, Br

ma.bistriche@gmail.com

https://orcid.org/0000-0002-3320-9148

\section{Rosalba Lopes}

Historiadora; Doutora em História pela Universidade Federal Fluminense - UFF (Niterói, $\mathrm{RJ}, \mathrm{Br})$.

Rua Cesário Alvim, 45/202 - Padre Eustáquio

30720-270 Belo Horizonte, MG, Br

rossalba.lopes@gmail.com

https://orcid.org/0000-0003-3618-4019 


\section{ARTIGOS}

ERotildes Maria Leal

Professora adjunta do Departamento de Medicina de Família e Comunidade da Universidade Federal do Rio de Janeiro - UFRJ (Rio de Janeiro, RJ, Br).

Rua Capitão Salomão 68/703 - Botafogo

22271-040 Rio de Janeiro, RJ, Br.

eroleal@gmail.com

https://orcid.org/0000-0002-8468-4571

This is an open-access article, which permits unrestricted use, distribution, and reproduction in any medium for non-commercial purposes provided the original authors and sources are credited.

Rev. Latinoam. Psicopat. Fund., São Paulo, 23(3), 620-645, set. 2020 